EESTI NSV TEADUSTE AKADEEMIA TOIMETISED. XVIII KÖIDE

KEEMIA * GEOLOOGIA. 1969. Nr. 1

ИЗВЕСТИЯ АКАДЕМИИ НАУК ЭСТОНСКОЙ ССР. ТОМ ХVІІ

ХимИЯ - ГЕОлоГия. 1969. № 1

К. ЛЭЭТС, АВО КОГЕРМАН

\title{
СИНТЕЗ ТЕРПЕНОВЫХ ПРОИЗВОДНЫХ АЦЕТОУКСУСНОГО И МАЛОНОВОГО ЭФИРОВ НА БАЗЕ ПРОДУКТОВ ТЕЛОМЕРИЗАЦИИ ИЗОПРЕНА
}

В последние годы разработан ряд методов синтеза терпенондов, имеющих промышленное значение. Одним из наиболее перспективных является синтез терпеноидов из нзопрена методом теломеризации последнего с его гидрохлоридами $\left[{ }^{1}\right]$ по схеме

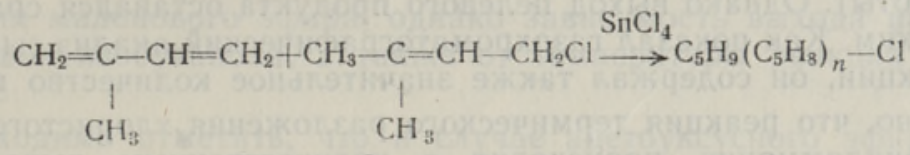

Полученные продукты теломеризации состоят в основном из моно- и сесквитерпежовых галоидопроизводных, содержащих соответственно около $50 \%$ геранилхлорида и $45 \%$ фарнезилхлорида. Как известно, эти соединения могут служить исходными веществами для получения многих ценных терпеноидных соединений. Однако использование продуктов теломеризации для синтеза затруднено вследствие содержания в них других изомерных терпеновых галоидопроизводных $\left[{ }^{2}\right]$.

Одним из нас был предложен метод селективного выделения указанных ценных лервичных аллильных хлоридов из синтетической смеси превращением носледних при взаимодействии диметиланилином в четвертичные соли аммония $\left[^{3}\right]$. Последние соединения могут біть легко очищены и выделены в безводном состоянни. В связи с этим представляло интерес изучение возможности С-алкилирования этими соединениями ацетоуксусного и малонового эфиров, так как этим способом можно было бы получить такие соединения, как геранилащетон - исходное вещество для синтеза ценных душистых веществ неролидола и фарнезола, а также фарнезилацетон (который является исходным продуктом для синтеза фитола, а последний - для синтеза витаминов Е и K) и еще некоторых соединений, представляющих интерес для промышленности.

Имеются данные о голучении геранилацетона алкилированием ацетоуксусного эфира синтетической смесыю хлоридов фракции $\mathrm{C}_{10}$ теломера $\left[{ }^{4}\right]$. Однако в этой работе зистота образовавшегося продукта достаточно не проверялась и авторам не удалось нз синтезированного ими геранилацетона получить кристаллический семикарбазон. По всей вероятности, полученный продукт был загрязнен изомерными соединениями.

Недавно мы предложили способ алкилирования ацетоуксусного и малонового эфиров четвертичными аммониевыми солями, содержащими замещенные аллильные радикалы $\left[{ }^{5}\right]$.

На основе предложенного способа нам удалось разработать методы синтеза пренил-, геранил- и фарнезилпроизводных ацетоуксусного и малоновых эфиров из гидрохлорида изопрена и продуктов его теломеризации. Ниже приводится подробное описание разработки и применения способа $\left[{ }^{5}\right]$ для синтеза описанных выше веществ.

Реакция алкилирования ацетоуксусного и малонового эфиров четвертичными аммониевыми солями мало изучена. Из немногочисленны 
опубликованных по этому вопросу трудов следует отметить работу Снайдера, Смита и Стюарта $\left[{ }^{6}\right]$, которые показали, что ацетоуксусные и малоновые эфиры бензилируются хлористым диметилфенилбензиламмонием.

Виттиг и сотрудники $\left[{ }^{7}\right]$ осуществили монометилирование малонового эфира этилатом тетраметиламмония.

В литературе до сих пор отсутствовали данные об алкилировании четвертичными аммониевыми солями, содержащими аллильные радикалы. Для изучения возможностей проведения упомянутой реакции с аллильными производными нами был выбран в качестве четвертичной аммониевой соли хлористый пренилдиметилфениламмоний, как низший гомолог соответствующих геранил- и фарнезилпроизводных.

В первых опытах алкилирования малонового эфира хлористым пренилдиметилфениламмонием была применена методика, аналогичная методике, наиболее широко применяемой при алкилировании малонового эфира галоидными алкилами $\left[{ }^{8}\right]$. Оказалось, что реакция алкилирования проходит в желаемом направлении и ведет к образованию пренилмалонового эфира (диэтилового эфира 4-метил-пентен-дикарбоновой$(1,1)$ кислоты). Однако выход целевого продукта оставался сравнительно невысоким. Как показал газохроматографический анализ сырого продукта реакции, он содержал также значительное количество примесей.

Известно, что реакция термического разложения хлористого пренилдиметилфениламмония происходит с количественным выходом при $110^{\circ} \mathrm{C}$. С целью повышения выхода продукта мы проводили реакцию при температуре кипения растворителя - изобутанола $\left(108^{\circ}\right)$. Оказалось, однако, что в этих условиях получался сильно загрязненный алкилат и выход целевого продукта был очень низким.

Это объясняется, вероятно, протеканием в присутствии изобутанола некоторых побочных реакций, например реакции образования пренилизобутилового эфира. В этих условиях возможна также реакция переэтерефикации малонового эфира и образование диизобутилового эфира пернилмалоновой кислоты. Поэтому в последующих опытах мы проводили реакцию алкилирования в отсутствие изобутанола. К раствору натриймалонового эфира в изобутаноле добавллли исходную четвертичную соль аммония и растворитель отгоняли в вакууме при температуре нагревательной бани не выше $35-40^{\circ}$. Разложением остатка в вакууме (5 мм рт. cr.) был получен пренилмалоновый эфир со значительно бо́льшими выходом и чистотой, чем при использовании описанных выше методик.

Представляло интерес выяснить также способность ионного соединения типа $\left[\mathrm{R}-\left(\mathrm{CH}_{3}\right)_{2} \mathrm{~N}-\mathrm{C}_{6} \mathrm{H}_{5}\right]^{+} i$ - $\mathrm{BuO}^{-}$алкилировать малоновый эфир. Для этого хлористый пренилдиметилфениламмоний был превращен в изобутилат пренилдиметилфениламмония

$$
\left[\mathrm{CH}_{3}-\mathrm{C}=\mathrm{CH}-\mathrm{CH}_{2}-\mathrm{N}-\mathrm{C}_{6} \mathrm{C}_{5}\right]^{(+)} \mathrm{Cl}^{(-)}+i-\mathrm{BuONa} \rightarrow
$$


Оказалось, что при прямом взаимодействии последнего с малоновым эфиром и последующем термическом разложении образуемого промежуточного соединения получается пренилмалоновый эфир примерно с таким же выходом и чистотой, как и при описанном выше способе.

Необходимо отметить, что пренилмалоновый эфир не во всех опытах выделялся в чистом виде, а в некоторых случаях его содержание в продуктах определялось методом газо-жидкостной хроматографии. Для идентификации пика пренилмалонового эфира применялся образец, синтезированный известным способом из изопрена $\left[{ }^{9}\right]$.

Чтобы дополнительно доказать строение полученного нами пренилмалонового эфира, он был превращен посредством омыления в пренилмалоновую кислоту (температура плавления последнего соответствовала указанной в литературе) и затем декарбоксилированием - в пренилуксусную кислоту $\left[{ }^{9}\right]$.

При изучении реакции алкилирования ацетоуксусного эфира хлористым пренилдиметилфениламмонием были испытаны аналогичные условия проведения реакции.

В этих опытах обнаружились те же закономерности, как и при алкилировании малонового эфира, однако зависимость выхода продукта от присутствия изобутанола, а также от температуры реакции оказалась меньшей.

Необходимо отметить, что в случае ацетоуксусного эфира во всех опытах получались алкилаты с гораздо большей чистотой, чем при алкилировании малонового эфира. Гладко проходило также алкилирование ацетоуксусного эфира изобутилатом пренилдиметилфениламмония.

Для доказательства строения синтезированного пренилацетоуксусного эфира он был превращен в метилгептенон, строение которого доказывалось по температуре плавления его семикарбазона $\left[{ }^{8}\right]$.

Результаты всех опытов алкилирования приведены в таблице.

Зависимость выхода продуктов алкилирования ацетоуксусного и малонового эфиров хлористым пренилднметилфениламмонием от условий проведения опыта

\begin{tabular}{|c|c|c|c|c|}
\hline \multirow{3}{*}{ Полученное соединение } & \multicolumn{4}{|c|}{ Выход, \% } \\
\hline & \multicolumn{4}{|c|}{ Метод } \\
\hline & A & Б & $\mathrm{B}$ & $\Gamma$ \\
\hline $\begin{array}{l}\text { Пренилмалоновый эфир } \\
\text { Пренилацетоуксусный эфир }\end{array}$ & $\begin{array}{l}44 \\
51\end{array}$ & $\begin{array}{l}56 \\
61\end{array}$ & $\begin{array}{l}17 \\
48\end{array}$ & $\begin{array}{l}50 \\
60\end{array}$ \\
\hline
\end{tabular}

П р и ме чан ие. Подробности о проведенин опытов по методам А, Б, В, Г приведены в экспериментальной части.

Поскольку применение металлического натрия, необходимого для проведения реакции данного типа, вызывает значительные трудности при осуществлении синтезов в промышленном масштабе, мы изучили возможность замены металлического натрия едким натром. Хорошие результаты дала методика, при которой изобутанол кипятили в небольшом вакууме с едким натром до полного растворения последнего, с одновременной отгонкой образовавшейся воды. Полученный раствор был успешно применен в реакции алкилирования.

Разработанная методика алкилирования на хлористом пренилдиметилфениламмонии была применена к алкилированию ацетоуксусного эфира четвертичными аммониевыми солями, содержащими радикалы высших гомологов пренилхлорида, - геранил- и фарнезилдиметилфе- 
ниламмонием. Последние выделялись из соответствующих фракций хлоридов теломера изопрена с его гидрохлоридами $\left[{ }^{10}\right]$.

Опыты алкилирования ацетоуксусного эфира хлористым геранилдиметилфениламмонием показали, что эта реакция также проходит гладко и кетонное расщепление получаемого геранилацетоуксусного эфира приводит к образованию геранилацетона даже с несколько большим выходом, чем в случае хлористого пренилдиметилфениламмония. Строение полученного геранилацетона доказано физико-химическими константами, газохроматографическим анализом (в качестве эталона применялся образец геранилацетона, синтезированный из природного линалоола известным способом $\left.\left[{ }^{8}\right]\right)$, а также по температуре плавления полученного из него семикарбазона.

Большой интерес представляет реакция алкилирования ацетоуксусного эфира хлористым фарнезилдиметилфениламмонием, так как получаемый в этой реакции (с последующим кетонным расщеплением) фарнезилацетон может быть использован для синтеза по известной методике изофитола - важнейшего компонента при получении синтетических витаминов Е и К. Поскольку фарнезилхлорид является по существу побочным продуктом при получении цитраля мегодом теломеризашии изопрена с его гидрохлоридами $\left[{ }^{10}\right]$, такой способ утилизации названного соединения значительно мог бы повысить рентабельность упомянутого выше метода.

При алкилировании ацетоуксусного эфира хлористым фарнезилдиметилфениламмонием, выделенным из фракции хлоридов $\mathrm{C}_{15}$ теломера $\left[{ }^{10}\right]$, с последующим прямым кетонным расщеплением полученного алкнлата был получен фарнезилацетон с удовлетворительным выходом.

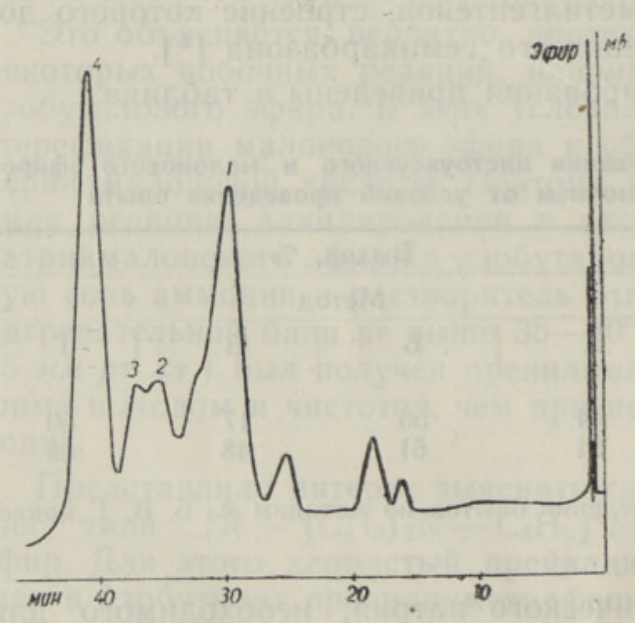

Рис. 1. Хроматограмма фарнезилаце тона:

1 - цис-цис-фарнезилацетон; 2 - цистранс-фарнезилацетон: 3 - транс-цис-фарнезнлацетон; 4 - транс-транс-фарнезилацетон

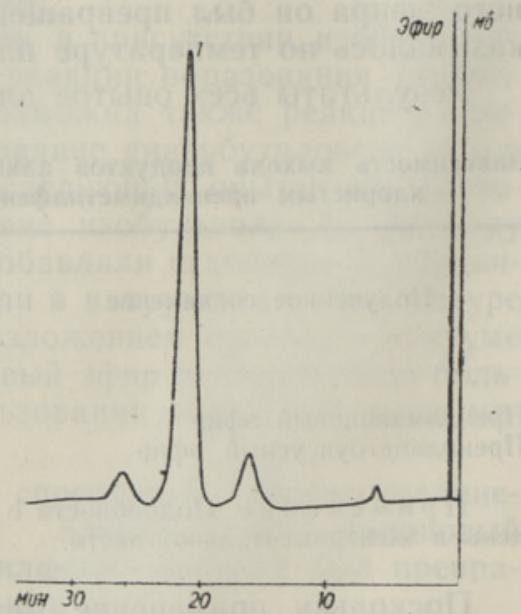

Рис. 2. Хроматограмма гексагидрофарнезилацетона:

1 - гексагндрофарнезилацетон.

Газохроматографическим анализом полученного продукта об́наружено четыре основных пика и немного примесей. Как известно, фарнезилацетон может существовать в виде четырех цис-транс-изомеров [ $\left.{ }^{11}\right]$. Можно было предполагать, что эти пики представляют соответствующие цис-транс-изомеры. Поскольку разделение указанных изомеров, а также 
нх синтез для эталона является весьма трудной задачей, мы решили превратить полученный фарнезилацетон путем гидрирования на $\mathrm{Pt}$-катализаторе в гексагидрофарнезилацетон, у которого цис-транс-изомерия отсутствует. Оказалось, что на газовой хроматограмме полученного гексагидрофарнезилацетона четыре основных пика соединились в один пик (см. рис. 1. и 2).

Содержание чистого гексагидрофарнезилацетона в синтезированном продукте составляло $88 \%$. Для доказательства строения гексагидрофарнезилацетона из него был получен семикарбазон. Очисткой последнего путем хроматографирования на $\mathrm{Al}_{2} \mathrm{O}_{3}$ и перекристаллизацией из метанола был получен семикарбазон с температурой плавления, указанной B $\left[{ }^{12}\right]$.

\section{ЭКСПЕРИМЕНТАЛЬНАЯ ЧАСТЬ}

\section{1. Получение хлористого пренилдиметилфениламмония}

291 г свежеперегнанного диметиланилина растворили в 308 г смеси изомерных гидрохлоридов изопрена, полученных взаимодействием изопрена с газообразным хлористым водородом $\left[{ }^{1}\right]$, содержащим $60 \%$ хлористого пренила (определялся по методу $\left[{ }^{13}\right]$ ). После выдерживания смеси при $20-25^{\circ}$ в течение 10 суток образовавшиеся кристаллы хлористого пренилдиметилфениламмония отфильтровали на нутч-фильтре, тщательно промыли петролейным эфиром и высушили в вакуум-эксикаторе.

Полученные кристаллы содержали $88 \%$ хлористого пренилдиметилфениламмоння (определялся по $\mathrm{Cl}^{-}$).

\section{2. Получение изобутилата натрия действием $\mathrm{NaOH}$ на изобутанол}

В круглодонной колбе, снабженной обратным холоднльником ДинаСтарка, нагревали в вакууме $\left(50\right.$ мм ) при $50^{\circ}$ в течение примерно 8 часов 150 мл изобутанола и 6 г едкого натра до полного растворения. После этого обратный холодильник сменили на нисходящий и отгоняли при этих же температуре и давлении 50 мл изобутанола до полного удаления влаги. Полученный продукт применялся непосредственно в реакции синтеза.

\section{3. Опыты алкилирования малонового эфира хлористым пренилдиметилфениламмонием}

Ме тод А. 4,0 г $\mathrm{NaOH}$ растворили в $100 \mathrm{M}$ изобутанола (по методике, описанной в пункте 2) и прибавили при перемешивании 17,6 2 малонового эфира, а затем 25,8 г хлористого пренилдиметилфениламмония (с содержанием чистого продукта $88 \%$ по $\mathrm{Cl}^{-}$) в растворе 30 мл изобутанола. Реакционная смесь нагревалась при перемешивании в течение б часов при $70^{\circ}$. Затем изобутанол отогнали в слабом вакууме и остаток вылили в 200 мл 5\%-го раствора $\mathrm{HCl}$. Органический слой извлекли петролейным эфиром, промыли раствором $\mathrm{NaHCO}_{3}$ и затем водой и высушили над $\mathrm{MgSO}_{4}$. Петролейный эфир отогнали и остаток перегнали в вакууме.

Получены две фракции: I с т. кип. 100-115 (6 мм), 10,25 2; II с т. кип. $115-125^{\circ}(6$ мм $), 6,65$ 2. Обе фракции анализировали методом газовой хроматографии и определяли в них содержание пренилмалонового 
эфира. Суммарное содержание пренилмалонового эфира в обеих фракциях 9,9 г (выход 44\%).

Метод Б. Реакция велась с таким же количеством реагентов, как при методике $\mathrm{A}$, но температура реакционной смеси была поднята до температуры кипения изобутанола $\left(108^{\circ}\right)$ и выдерживалась 3 часа. После выделения продукта аналогично вышеописанному было получено 15 г фракции с т. кип. $100-123^{\circ}$ (6 мм), содержащего, по данным газохроматографического анализа, $26 \%$ пренилмалонового эфира. Выход гренилмалонового эфира 3,8 г (17\%).

Метод В. Такое же количество реагентов, как и в двух предыдущих опытах, смешали в круглодонной колбе. Затем изобутанол отогнали в вакууме $(20-15$ мм) при температуре нагревательной бани не выше $40^{\circ}$. После удаления изобутанола вакуум углубили до 5 мм и температуру реакционной смеси подняли до 110-115․ Реакционную смесь выдерживали при этой температуре до прекращения выделения диметиланилина. К остатку добавили 50 мл дистиллированной воды, и органический слой извлекли петролейным эфиром. Экстракт промыли $5 \%$-ным $\mathrm{HCl}$, затем насыщенным раствором $\mathrm{NaHCO}_{3}$ и наконец дистиллированной водой до нейтральной реакции. После сушки над $\mathrm{MgSO}_{4}$ отогнали петролейный эфир и остаток перегнали в вакууме. Получено 21,4 г фракции с т. кип. $100-128^{\circ}(6$ мм), содержавшей $61 \%$ пренилмалонового эфира. Выход чистого пренилмалонового эфира 13,05 г (57\%).

М е тод Г. 3,0 г $\mathrm{NaOH}$ растворили в 75 мл изобутанола. При охлаждении холодной водой $\left(10^{\circ}\right)$ и перемешивании добавили по каплям 21 己 хлористого пренилдиметилфениламмония в растворе 50 мл изобутанола (сразу же началось выделение осадка хлористого натрия). Затем добавили, также при перемешивании, 13,0 г малонового эфира. Изобутанол отогнали в вакууме $\left(\sim 17\right.$ мм ) при температуре бани не выше $40^{\circ}$. Затем вакуум углубили до 5 мм, температуру подняли до $110-115^{\circ}$ и выдерживали до прекращения отгонки диметиланилина.

При охлаждении к остатку (который содержал осадок $\mathrm{NaCl}$ и органический слой) добавили 100 мл дистиллированной воды. Органический слой извлекли петролейным эфиром, экстракт промыли несколько раз $5 \%$-ной $\mathrm{H}_{2} \mathrm{SO}_{4}$, затем раствором $\mathrm{NaHCO}_{3}$ и дистиллированной водой до нейтральной реакции. После сушки над $\mathrm{MgSO}_{4}$ петролейный эфир отогнали, а остаток перегнали в вакууме. Получено 15,9 г фракции с т. кип. $100-123^{\circ}$ (3 мм). Содержание пренилмалонового эфира во фракцин 8,6 г (выход 50\%)

\section{4. Омыление пренилмалонового эфира}

$1 \overline{2}, 5$ г фракции пренилмалонового эфира (с содержанием продукта $86 \%$ ) растворили в 13 мл этанола и прибавили раствор 9,7 г КОН в смеси 20 мл этанола и 17 мл воды. Реакционную смесь нагревали на кипящей водяной бане 12 часов. Затем отогнали этанол, а остаток после охлаждения подкислили соляной кислотой и трижды проэкстрагировали эфиром. Эфирный экстракт высушили над $\mathrm{MgSO}_{4}$ и эфир отогнали. Был получен жидкий остаток, который после охлаждения закристаллизовался. Перекристаллизацией из смеси петролейного эфира с бензолом (1:1) получено 3,6 г белых кристаллов с т. пл. 95-96, представляющих собой пренилмалоновую кислоту (4-метилпентен-(3) -дикарбоновую-(1,1) кислоту). По литературным данным $\left[{ }^{9}\right]$, температура плавления чистой пренилмалоновой кислоты $96^{\circ}$. 


\section{5. Декарбоксилирование пренилмалоновой кислоты}

3,5 г пренилмалоновой кислоты нагревали в колбе с обратным холодильником при $160^{\circ}$ в течение 1,5 часа. После охлаждения полученный продукт проэкстрагировали 35 м 10\%-ного водного раствора $\mathrm{NaHCO}_{3}$, а затем эфиром, эфирный слой отделили, а к водному прибавили при охлаждении 30 мл $5 \%$-ной $\mathrm{HCl}$ и потом экстрагировали петролейным эфиром. Петролейно-эфирную вытяжку высушили над $\mathrm{MgSO}_{4}$. После отгонки петролейного эфира остаток перегнали в вакууме. Получено 1,4 2 (выход 55\%) пренилуксусной кислоты с т. кип. $95-96^{\circ}(1 \mathrm{MM})$, $n_{L^{20}} 1,4460$.

6. Алкилирование ацетоуксусного эфира хлористым пренилдиметилфениламмонием

Опыты по алкилированию ацетоуксусного эфира хлористым пренилдиметилфениламмонием проводились аналогично алкилированию малонового эфира по методам А, Б, В и Г.

Содержание в продуктах реакции пренилацетоуксусного эфира также определялось методом газовой хроматографии. Результаты опытов приведены в таблице.

\section{7. Қетонное расщепление пренилацетоуксусного эфира (получение метилгептенона)}

K 9,1 г фракции пренилацетоуксусного эфира с содержанием 92\% чистого продукта добавили $75 \mathrm{M} \Omega$ 10\%-ного раствора $\mathrm{NaOH}$. Реакционную смесь перемешивали при $70^{\circ} 4$ часа, затем охладили и подкислили конц. $\mathrm{HCl}$. Выделившийся органический слой отделили, а водный слой несколько раз проэкстрагировали эфиром. Объединенный эфирный раствор промыли несколько раз насыщенным раствором бикарбоната натрия, затем водой и высушили над сульфатом магния. После отгонки эфира остаток перегнали в вакууме. Получено 4,6 г (выход 86\%) метилгептенона с т. кип. $72-73^{\circ}(25$ мм $), n_{D}{ }^{20} 1,4405$.

\section{8. Получение семикарбазона метилгептенона}

Из 1 г синтезированного метилгептенона получен обычным способом семикарбазон с т. кип. $135^{\circ}$. По литературным данным $\left[{ }^{8}\right]$, температура плавления семикарбазона метилгептенона $135-136^{\circ}$.

\section{9. Получение хлористых геранил- и фарнезилдиметил- фениламмония}

Для синтеза хлористых геранил- и фарнезилдиметилфениламмония использовался теломер изопрена с его гидрохлоридами $\left[{ }^{1,10}\right]$, полученный при глубине теломеризации $25 \%$. Из суммарного теломера перегонкой в вакууме $\left(2-3\right.$ мм, т. кип. $\left.60-85^{\circ}\right)$, на кнпящей водяной бане выделили фракцию хлоридов $\mathrm{C}_{10}$. Из остатка в вакууме отогнали с перегретыми парами этиленгликоля фракцию хлоридов $\mathrm{C}_{15}\left[{ }^{10}\right]$.

Из этих фракций при взаимодействин с диметиланилином получили соответственно хлористый геранил- и фарнезилдиметилфениламмоний ло ранее описанной методике $\left[{ }^{10}\right]$. 
10. Алкилирование ацетоуксусного эфира хлористым геранилдиметилфениламмонием

8,2 г $\mathrm{Na}$ растворили в 300 мл изобутанола. Полученный раствор охладили до $10^{\circ}$ и при перемешивании постепенно добавляли 50,0 г ацетоуксусного эфира. Затем, продолжая перемешивание, добавили при той же температуре 104,5 г хлористого геранилдиметилфениламмония (с содержанием 8,5\% $\mathrm{Cl}^{-}$). После перемешивания в течение 1 часа при комнатной температуре отогнали в вакууме $(20-15$ мм) изобутанол при температуре нагревательной бани не выше $50^{\circ}$. Остаток разложили в вакууме $\left(5\right.$ мм) при температуре $110-115^{\circ}$. Разложение велось до прекращения выделения диметиланилина. После охлаждения остаток вылили в 200 мл воды, проэкстрагировали петролейным эфиром и эфирную вытяжку промыли $10 \%$-ным раствором $\mathrm{HCl}$, затем водой до нейтральной реакции и высушили над $\mathrm{MgSO}_{4}$. После отгонки петролейного эфира к остатку добавили 500 мл 10\%-ного раствора КОН и смесь перемешивали в течение 6 часов на кипящей водяной бане. После охлаждения разбавили водой и проэкстрагировали петролейным эфиром, затем эфирную вытяжку промыли водой и высушили над $\mathrm{MgSO}_{4}$. После отгонки петролейного эфира остаток перегнали в вакууме. Получено $3 \mathrm{I}, 0$ 2 (выход 62,5\%) геранилацетона с т. кип. 95-96 $\left(2\right.$ мм), $n_{D}{ }^{20} 1,4678$, $d_{4}{ }^{20} 0,8680$; т. пл. семикарбазона $92^{\circ}$, что согласуется с данными литературы $\left[{ }^{8}\right]$.

\section{1. Алкилирование ацетоуксусного эфира хлористым} фарнезилдиметилфениламмонием

По методике, аналогичной описанной в предыдущем пункте, из 53,3 г хлористого фарнезилдиметилфениламмония (с содержанием 6,0\% $\mathrm{Cl}^{-}$), 3,38 г $\mathrm{Na}$ и 21 г ацетоуксусного эфира получено 14,5 г (выход 53,5\%) сырого фарнезилацетона с т. кип. $128-142^{\circ}(1,5 \mathrm{MM}), n_{D}{ }^{20} 1,4780, d_{4}{ }^{20}$ 0,8785 .

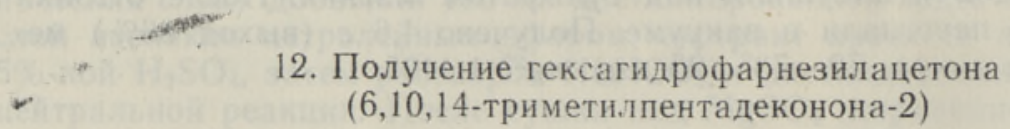

10 г сырого фарнезилацетона гидрировали в растворе 20 мл метанола в присутствии 0,1 г катализатора Адамса $\left[{ }^{14}\right]$, при избыточном давлении водорода 50 мм вод. ст. После заметного поглощения водорода добавили еще 0,05 г катализатора и гидрировали до прекращения поглощения водорода. Затем отфильтровали катализатор, отогнали метанол и остаток перегнали в вакууме. Получено 7,5 г (выход 75\%) гексагидрофарнезилацетона с т. кип. $129-136^{\circ}$ (1 мм), $n_{D}^{20} 1,4476$.

\section{3. Получение семикарбазона гексагидрофарнезилацетона}

2,8 г полученного гексагидрофарнезилацетона растворили в 30 мл $95 \%$-ного этанола, прибавили 1,75 г солянокислого семикарбазида и 2,2 а уксуснокислого натрия. Затем реакционную смесь нагревали 2 часа на кипящей водяной бане и оставили стоять при комнатной температуре в течение суток. После этого отогнали в небольшом вакууме этанол. К остатку добавили дистиллированную воду и водный раствор многократно проэкстрагировали эфиром. Эфирную вытяжку высушили над. 
$\mathrm{MgSO}_{4}$ и эфир отогнали. В остатке было получено 2 г маслообразного вродукта, который растворили в 100 мл смеси эфира с петролейным зфиром (1:1) и хроматографировали на 50 г $\mathrm{Al}_{2} \mathrm{O}_{3}$. Получено:

\begin{tabular}{|c|c|c|c|c|}
\hline Фракция & Растворитель & & $\begin{array}{c}\text { Количество, } \\
\text { мл }\end{array}$ & Элюат \\
\hline 1 & Петролейный эфир-эфир & 1: & 200 & 0,3 г, желтоватые кристаллы \\
\hline 2 & То же & $1: 3$ & 230 & 0,7 г, белые кристаллы \\
\hline 3 & Эфнр & & 150 & 0,2 2,,$\quad$, \\
\hline 4 & Метанол & & 200 & 0,4 , коричневое масло \\
\hline
\end{tabular}

Элюат фракции 2 растворили в 3 мл метанола и оставили стоять при температуре $0^{\circ}$. Выпавшие кристаллы отфильтровали (при температуре $0^{\circ}$ ) и еще раз перекристаллизовали из метанола. Получили 0.3 г белых кристаллов с т. кип. $66-67^{\circ}$. По литературным данным температура плавления семикарбазона гексагидрофарнезилацетона $67,5-68^{\circ}$ $\left[{ }^{12}\right]$.

14. Методика газохроматографического анализа продуктов алкилирования

Bce анализы были проведены на газовом хроматографе «Хром-I» ироизводства фирмы «Лабораторне Пристрое» ЧССР. Применялась колонка длиной 2,5 м, внутренним диаметром 4 мм. В качестве жидкой фазы использовался полиэтиленгликоль 4000, нанесенный на твердый адсорбент хромосорб W (30-70 меш). Газом-носителем служил аргон, подаваемый со скоростью $10 \mathrm{~m} /$ мин. Қоличество пробы 0,1 мкл. Рабочая температура при анализе пренилмалонового и пренилацетоуксусного эфиров $160^{\circ}$, при анализе фарнезилацетона и гексагидрофарнезилацетона $180^{\circ}$.

\section{Выводы}

1. Изучена реакция алкилирования малонового и ацетоуксусного эфиров четвертичными аммониевыми ионами, содержащими радикалы аллильного типа.

2. Найдено, что при этом образуются соответствующие С-алкилзамещенные малоновые и ацетоуксусные эфиры.

3. Установлено, что наиболее высокие выходы могут быть получены при термическом разложении соединений четвертичных аммониевых ионов с малоновым и ацетоуксусным эфирами в отсутствне растворителя.

4. Разработана методика алкилирования с применением едкого натра вместо металлического натрия.

5. Разработан новый метод алкилирования замещенными аллильными галоидопроизводными малонового и ацетоуксусного эфиров с использованием соединений этих галоидопроизводных и диметиланилина.

6. Разработан метод получения геранилацетона и фарнезилацетона из соответствующих фракций продуктов теломеризации изопрена с его гидрохлоридами. Гидрированием фарнезилацетона получен 6,10,14-триметилпентадеканон-2 - полупродукт для синтеза витамина Е. 
ЛИ Т Е Р А Т У А

1. Л э э т с К. В., ЖОХ, 28, 1823 (1958).

2. Л э э т с K. В., ЖОХ, 28, 3096 (1958).

3. Лээт с К. В., Авт. свид. СССР, № $128860,1959$.

4. Петров А. А., Бунина-Криворукова Л. И., ЖОХ, 30, 1165 (1960).

5. Л ээт с К. В., Коге р ман А. П., Авт. свид. СССР, № 184267, 1966; Бюлл. изобр., № 15 (1966).

6. Snyder H. R., a. o. J. Am. Chem. Soc., 66, 200 (1944).

7. Wittig G. a. o., Ann., 557, 201 (1947).

8. Н а з а ров: И. Н. и др., ЖОХ, 28, 1444 (1958).

9. St a udinger H., Helv. him. acta, 5, 743 (1922).

10. Лэз т с К. В., ЖОХ, 31, 1869 (1961).

11. Is le r O. a. o., Helv. him. acta, 41, 786 (1958).

12. Meyer H., Gabor U., I sler O., Rüegg R., Wiss O., Helv. him. acta, 47, 201 (1964).

13. Л э э т с К. В. и др., ЖОХ, 27, 2969 (1957).

14. Синтезы органических препаратов, Сб. І, М., ИЛ, 1949, с. 357.

\author{
Ннститут химии \\ Академии наук Эстонской ССР \\ Поступила в редакиию \\ $11 /$ IV 1968
}

\title{
K. LAATS, AVO KOGERMAN
}

\section{ATSEETAADIKESTRI- JA MALOONESTRI TERPEENDERIVAATIDE SUNTEESIMINE ISOPREENI TELOMERISATSIOONIPRODUKTIDEST}

Esitatakse atseetäädikestri C-alküülimise uus meetod prenüül-, geranüül- ja farnesüüldimetüülfenüülammooniumkloriididega, mille abil oli vōimalik sünteesida geranüülatsetooni ja farnesüülatsetooni isopreenist ja tema hüdrokloriidide telomerisatsiooniproduktidest ning metüülheptenooni isopreeni hüdrokloriidist. Telomeerist sünteesitud farnesüülatsetooni hüdreerimisel saadi heksahüdrofarnesüülatsetooni, mida on vōimalik kasutada sünteetilise E-vitamiini lähteainena. On välja töötatud metoodika maloonestri alküülimiseks prenüüldimetüülfenüülammooniumkloriidiga.

\section{K. LÄATS, AVO KOGERMAN}

\section{SYNTHESIS OF ACETOACETIC AND MALONIC ESTERS TERPENIC DERIVATIVES FROM TELOMERIZATION PRODUCTS OF ISOPRENE}

A new C-alkylation method of acetoacetic ester with prenyl, geranyl and farnesyl dimethylphenyl ammonium chlorides is described. In consequence of this it has become possible to obtain a preparation of geranyl acetone and farnesyl acetone from the telomerization products of isoprene with its hydrochlorides as well as methyl heptenone from isoprene hydrochloride. By hydrogenization of farnesyl acetone, hexahydrofarnesyl acetone has been synthesized. The alkylation of malonic ester with prenyldimethylphenyl ammonium chloride has also been studied. 